\title{
Applying bioethical principles for directing investment in precision medicine.
}

\begin{abstract}
The concept of precision medicine aims to tailor treatment based on data unique to the patient. An example is the use of genetic data from malignant tumours to select the most appropriate oncological treatment. The competing interests of utilitarianism and egoism create dilemmas for decisions regarding investment in precision medicine. The need to balance the perceived rights and needs of individuals against those of society as a whole is an on-going challenge in the distribution of limited health service resources.
\end{abstract}

Precision medicine describes the use of biomarker data from companion diagnostics to highlight a subsection of a specific cohort of patients who might respond to a particular treatment. ${ }^{1}$ Companion diagnostics can take a number of forms and include testing modalities such as immunohistochemistry and genetic sequencing. The stratified medicine approach is often used in an oncological setting for patients with late stage malignancies who have a guarded prognosis. Oncological treatments linked to companion diagnostics in this way are novel and expensive. This is an active area of medical research and there are likely to be new drugs provided by the NHS that use companion diagnostics with resulting potential for increased financial burden to the NHS. It is therefore important to consider the ethical principles that underpin any such investment.

This essay will focus on ethical issues relating to companion diagnostics in cancer patients and consider arguments for and against how to direct investment using opposing consequentialist theories of ethical egoism and utilitarianism.

The first issue in relation to use of companion diagnostics in personalised medicine is who decides whether to test or not. Within the NHS most of these decisions are taken at the multidisciplinary team (MDT) meeting as a 
collective decision between physicians, nursing staff, oncologist, radiologist and pathologist. These are multifaceted decisions that take into consideration a number of factors such as the histological subtype of cancer, patient performance status, prognosis, social circumstances and patient wishes. This process excludes the patient themselves in a way that is considered counter to patient autonomy, a key bioethical principle underpinning patient care. ${ }^{2}$ There is a strong argument for including patient advocates and or the patients themselves in MDT meeting to allow them to contribute to decision making and that this would be in keeping with GMC guidelines of good practice..$^{2-4}$ However, this would be impractical given the additional time that would take.

Patient autonomy is a key bioethical principle in medical practice ${ }^{3,5}$ and describes patients having the ability to freely choose and determine their fate with independence. ${ }^{6}$ The freedom to make a choice based purely on ones' own self interest would align with Smith's theory that pursuit of self-interest ultimately results in good for all society as if by "an invisible guiding hand"7 and this forms the basis for the consequentialist theory of ethical egoism. Patient autonomy requires that patients are in possession of the full facts of their case presented in a clear and understandable way without biased interference by doctors or family members. ${ }^{8}$ Patient autonomy is, however, respected when patients are offered treatment by an oncologist, as long as the information provided is accurate and full. There is no evidence in the medical literature around how many patients decline this specific precision therapy in the UK. In the US, however, there is evidence that patients who pay for their own treatment have a reduced compliance rate due to high costs. ${ }^{9}$ Provision of health services by the NHS on a basis of need rather than the ability to pay means that this situation is unlikely to occur in the UK.

A further issue around precision medicine concerns who decides what to invest in and how. In the UK these decisions are taken by the state; by government who direct health policy and by executives who manage the NHS. The NHS is generally guided by fundamental principles of utilitarianism and 
described by Mill (1871) as the best use of resources for the greatest good within the population. ${ }^{10-12}$ Whilst on the surface precision medicine using companion diagnostics appears to fit with this principle very well; using expensive drugs only in those patients who are likely to benefit. However, the high cost of these medications may tip the balance in favour of noninvestment in this technology in favour of cheaper preventative measures. ${ }^{13}$

Prescribing expensive novel oncotherapeutic agents linked to companion diagnostics will reduce therapy costs compared with providing the treatment to all patients and there is a wealth of evidence demonstrating that such agents are effective. Examples include the use of tyrosine kinase inhibitors (TKI) in the treatment of advanced adenocarcinoma of the lung ${ }^{14-16}$ and checkpoint inhibitors in non-small cell lung cancer. ${ }^{17}$ These agents can give overall survival benefits of 13 months and between 14-17months respectively when used in the setting of lung cancer. ${ }^{14,17}$ It is difficult to argue against the deontological principle of a right to life ${ }^{18}$ and every patient with a terminal illness is likely to feel strong leanings towards egoism when considering their own mortality. However, from a utilitarian perspective it may be of more benefit to more people to redirect the large sums of money involved in funding these novel oncotherapies towards diagnosis and treatment of medical conditions affecting a larger number of patients with a longer survival benefit than a year or so. Many of these oncological drugs have been approved for use in the NHS by the National Institute of Health and Care Excellence (NICE). It is evident that emotive arguments from the few can influence decision making by the state through the media and court action as was the case with Herceptin. ${ }^{19}$ The government and the media were criticised by the medical profession at the time for not being able to step back from individual terminal cancer cases and make resourcing decisions for the benefit of the many. ${ }^{13}$

Investment would be required to ensure that precision medicine services are of sufficient quality to be reliable and this would include, staffing, equipment 
and processes that comply with clinical standards. There is a conflict that arises when balancing quality, costs and timeliness in the diagnosis of lung cancer. ${ }^{20}$ Greater efficiencies are said to occur with larger batches of tests and centralisation of services in large, single centres. ${ }^{21-23}$ There is a counter argument to this approach when one considers slow turnaround times resulting from batching of diagnostic tests. ${ }^{24}$ Again, using the example of lung adenocarcinoma, it is now possible to perform EGFR receptor mutational analysis using a fully automated, clinically validated real-time PCR platform that yields results in under 3 hours. ${ }^{25}$ This service would require investment in technology and staff training but has clear benefits for patients who may deteriorate in the 2-3 week wait for results from a centralised laboratory. Being able to offer tyrosine kinase inhibitor therapy relies upon patients being well enough to receive the treatment. ${ }^{26,27}$ Inevitably some people will be denied effective treatment for a fatal disease if they have to wait too long for their genetic results through a cost efficient, large throughput centralisation model.

There has been considerable investment in developing accurate biomarkers by pharmaceutical companies developing companion diagnostics and oncological therapies. PD-L1 is a good example of this where different clones of immunohistochemistry have been assessed to identify the most accurate test. ${ }^{28}$ Investment has also been directed towards training histopathologists to interpret these tests and reduce interobserver variation for what is a subjective report. ${ }^{28}$

It is possible that patients may perceive discrimination when looking at the observable characteristics of individuals receiving TKI therapy for adenocarcinoma of the lung. This is because the somatic genetic mutation within the tumour occurs with greater frequency in young, females who have never smoked. ${ }^{29}$ The differences in patient smoking status may be misconstrued and perceived as bias by a treating organisation on the basis of what is perceived by society to be a harmful lifestyle for which taxpayers bear 
the cost. ${ }^{30}$ It may be useful to investors in this area to consider the possibility for misconception by patients. This risk may be mitigated against by the production of detailed patient information leaflets freely available in the oncology outpatient waiting room.

There is an increased incidence of patients requesting histopathological samples of their cancer to be sent for direct-to-consumer (DTC) genomic testing. ${ }^{31}$ The reasons for this are unclear but patients with cancer are often in discussion groups both online and in person for emotional and social support. Whilst these networks are undoubtedly beneficial in psychosocial and even survival respects they may highlight differences in treatment options that exists across different tumour types. ${ }^{32}$ Autonomy, dignity and integrity and mortal desperation all drive the need to explore treatment options, including untested experimental ones. This is an example of self-interest pursuit that underpins ethical egoism and drives, in part, the direct-to-consumer (DTC) genetic testing market. This is at odds with utilitarian principles that form the basis of workings in the NHS. Reports generated by DTC companies have the potential to create conflict between patients and the NHS depending upon what they are able to prescribe according to current NICE guidelines. ${ }^{31,33,34}$ Meadowcroft argues that governments have a responsibility to restrict market forces that exploit vulnerable patients who pay for tumour genomic information in a context of a terminal cancer diagnosis. ${ }^{35}$ In addition there are problems with knowing the relevance and risk that identification of variation by genomic analysis raises and the general consensus amongst medical professional is that patients should be discouraged from using these services until such time the full implication of their findings is known and evidence based. ${ }^{36}$ The counter argument is that restricting DTC genetic testing undermines respect for patient autonomy. ${ }^{34}$

Patients are also using direct to consumer testing for predicting future cancer risk. ${ }^{37}$ "Expert advice" received in the accompanying DTC genetic reports can be inaccurate and misleading ${ }^{36}$ and there is also evidence that people do not necessarily change their risk behaviours in accordance with the information 
they receive. ${ }^{38}$ These are usually healthy people who are receiving information about risk associated with single nucleotide variation linked with multifactorial risk of cancers such as colorectal cancer. ${ }^{39}$ Again, full understanding of how a person's genes interact with the environment to determine precise risk of developing such cancer is not fully understood and the provision of direct to consumer genomic testing is not regulated. ${ }^{34,40}$ Some of these arguments are used to support the call for increased regulation of the DTC genetic testing industry. ${ }^{36}$

What may not be fully considered before taking up direct to consumer testing in a setting of malignancy is the potential for identification of mutations that carry implications for family members through the germline. ${ }^{41}$ There are many genes that have been shown to have implications for germline inheritance that may be identified during testing for somatic mutations in cancers, ${ }^{41}$ and the best characterised of these is BRCA1/2 associated breast and ovarian cancer syndrome. ${ }^{42-44}$ As well as dealing with the uncertainty around infrequently encountered genetic variants and knowing how they translate into phenotype there is also the need to provide genetic counselling before testing so that patients can make and informed choice, not only for themselves but also for family members. ${ }^{36}$ This requirement is based on the principle for patient autonomy and informed consent. Patients (and their family members) can only make a choice based upon adequate information before they proceed. ${ }^{45,46}$ Testing and referral to genetic counselling after the event of revealing a genetic variant creates difficulties for professionals and their relationships with patients in an outpatient clinic by undermining this principle. ${ }^{47}$ Genetic testing without prior patient consent denies patients an opportunity not to know the findings. ${ }^{45,48}$ There is a need for investors in precision medicine to ensure there are enough genetic counsellors and clinic time to cope with the inevitable increased demand that precision medicine and genetic testing of malignant tumours will bring. ${ }^{46}$ 
In conclusion, the competing interests of utilitarianism and egoism create dilemmas for decisions regarding investment in precision medicine. The need to balance the perceived rights and needs of individuals against those of society as a whole is an on-going challenge in the distribution of limited health service resources.

\section{References}

1. Brown NA, Aisner DL, Oxnard GR. Precision Medicine in Non-Small Cell Lung Cancer: Current Standards in Pathology and Biomarker Interpretation. Am Soc Clin Oncol Educ Book 2018(38):708-15. doi: 10.1200/EDBK_209089 [published Online First: 2018/09/21]

2. Thornton S. Time to review utility of multidisciplinary team meetings. BMJ 2015;351:h5295. doi: 10.1136/bmj.h5295 [published Online First: 2015/10/09]

3. General Medical Council (Great Britain). Good medical practice. Manchester: General Medical Council 2013.

4. Taylor C, Munro AJ, Glynne-Jones R, et al. Multidisciplinary team working in cancer: what is the evidence? BMJ 2010;340:c951. doi: 10.1136/bmj.c951 [published Online First: 2010/03/25]

5. Beauchamp TL, Childress JF. Principles of biomedical ethics. 7th ed. New York ; Oxford: Oxford University 2013.

6. Gillon R. Philosophical Medical-Ethics - Where Respect for Autonomy Is Not the Answer. Brit Med J 1986;292(6512):48-49. doi: DOI 10.1136/bmj.292.6512.48

7. Smith A, Spencer MG. Wealth of nations. Ware: Wordsworth 2012.

8. Hope RA. Medical ethics a very short introduction. Very short introduction 114. Oxford ; New York: Oxford University Press, 2004:152 p.

9. Hess LM, Louder A, Winfree K, et al. Factors Associated with Adherence to and Treatment Duration of Erlotinib Among Patients with Non-Small Cell Lung Cancer. J Manag Care Spec Pharm 2017;23(6):643-52. doi: 10.18553/jmcp.2017.16389 [published Online First: 2017/05/23]

10. Mill JS. Utilitarianism. 4th ed. ed. [S.l.]: Longmans 1871.

11. Heath I. Back to the future: aspects of the NHS that should never change-an essay by Iona Heath. BMJ 2018;362:k3187. doi: 10.1136/bmj.k3187 [published Online First: 2018/07/27]

12. Vetter N, Matthews I. Epidemiology and public health medicine. Edinburgh ; New York: Churchill Livingstone 1999. 
13. Barrett A, Roques T, Small M, et al. How much will Herceptin really cost? BMJ 2006;333(7578):1118-20. doi: 10.1136/bmj.39008.624051.BE [published Online First: 2006/11/25]

14. Urata Y, Katakami N, Morita S, et al. Randomized Phase III Study Comparing Gefitinib With Erlotinib in Patients With Previously Treated Advanced Lung Adenocarcinoma: WJOG 5108L. J Clin Oncol 2016;34(27):3248-57. doi: 10.1200/JC0.2015.63.4154 [published Online First: 2016/03/30]

15. Fukuoka M, Yano S, Giaccone G, et al. Multi-institutional randomized phase II trial of gefitinib for previously treated patients with advanced non-smallcell lung cancer (The IDEAL 1 Trial) [corrected]. J Clin Oncol 2003;21(12):2237-46. doi: 10.1200/JC0.2003.10.038 [published Online First: 2003/05/16]

16. Kris MG, Natale RB, Herbst RS, et al. Efficacy of gefitinib, an inhibitor of the epidermal growth factor receptor tyrosine kinase, in symptomatic patients with non-small cell lung cancer - A randomized trial. Jama-J Am Med Assoc 2003;290(16):2149-58. doi: DOI 10.1001/jama.290.16.2149

17. Herbst RS, Baas P, Kim DW, et al. Pembrolizumab versus docetaxel for previously treated, PD-L1-positive, advanced non-small-cell lung cancer (KEYNOTE-010): a randomised controlled trial. Lancet 2016;387(10027):1540-50. doi: 10.1016/S0140-6736(15)01281-7 [published Online First: 2015/12/30]

18. Holland S. Bioethics : a philosophical introduction. Cambridge: Polity Press 2003.

19. Kondro W, Sibbald B. Patient demand and politics push Herceptin forward. CMAJ 2005;173(4):347-8. doi: 10.1503/cmaj.050883 [published Online First: 2005/08/17]

20. Jacobsen MM, Silverstein SC, Quinn M, et al. Timeliness of access to lung cancer diagnosis and treatment: A scoping literature review. Lung Cancer 2017;112:156-64. doi: 10.1016/j.lungcan.2017.08.011 [published Online First: 2017/12/02]

21. Dixon J. Modernizing the NHS. Performance and productivity. BMJ 2000;320(7247):1462-4. [published Online First: 2000/05/29]

22. Dixon J, Street A, Allwood D. Productivity in the NHS: why it matters and what to do next. BMJ 2018;363:k4301. doi: 10.1136/bmj.k4301 [published Online First: 2018/10/28]

23. Carter of Coles PRCB. Operational productivity and performance in English NHS acute hospitals : unwarranted variations. . An independent report for the Department of Health by Lord Carter of Coles. London: Department of Health 2016.

24. Young T, Brailsford $S$, Connell C, et al. Using industrial processes to improve patient care. BMJ 2004;328(7432):162-4. doi: 10.1136/bmj.328.7432.162 [published Online First: 2004/01/17]

25. Lambros L, Uguen A. Toward a Molecular Diagnosis in a Single Day for Patients With Advanced Non-small-cell Lung Cancer. Clin Lung Cancer 2018;19(5):e537-e38. doi: 10.1016/j.cllc.2018.03.002 [published Online First: 2018/05/29]

26. Giaccone G. The role of gefitinib in lung cancer treatment. Clin Cancer Res 2004;10(12 Pt 2):4233s-37s. doi: 10.1158/1078-0432.CCR-040005 [published Online First: 2004/06/26] 
27. Sohal DP, Rini BI, Khorana AA, et al. Prospective Clinical Study of Precision Oncology in Solid Tumors. J Natl Cancer Inst 2015;108(3) doi: 10.1093/jnci/djv332 [published Online First: 2015/11/11]

28. Hirsch FR, McElhinny A, Stanforth D, et al. PD-L1 Immunohistochemistry Assays for Lung Cancer: Results from Phase 1 of the Blueprint PD-L1 IHC Assay Comparison Project. J Thorac Oncol 2017;12(2):208-22. doi: 10.1016/j.jtho.2016.11.2228 [published Online First: 2016/12/04]

29. Midha A, Dearden S, McCormack R. EGFR mutation incidence in non-smallcell lung cancer of adenocarcinoma histology: a systematic review and global map by ethnicity (mutMapII). Am J Cancer Res 2015;5(9):2892-911. [published Online First: 2015/11/27]

30. Burley J, Harris J. A companion to genethics. Blackwell companions to philosophy. Oxford: Blackwell, 2002.

31. Bellcross CA, Page PZ, Meaney-Delman D. Direct-to-consumer personal genome testing and cancer risk prediction. Cancer J 2012;18(4):293-302. doi: 10.1097/PP0.0b013e3182610e38 [published Online First: 2012/08/01]

32. Spiegel D. Mind matters in cancer survival. Psychooncology 2012;21(6):58893. doi: 10.1002/pon.3067 [published Online First: 2012/03/23]

33. McGuire AL, Burke W. Health system implications of direct-to-consumer personal genome testing. Public Health Genomics 2011;14(1):53-8. doi: 10.1159/000321962 [published Online First: 2010/11/13]

34. McGuire AL, Burke W. An unwelcome side effect of direct-to-consumer personal genome testing: raiding the medical commons. JAMA 2008;300(22):2669-71. doi: 10.1001/jama.2008.803 [published Online First: 2008/12/11]

35. Meadowcroft J. The ethics of the market. Basingstoke: Palgrave Macmillan 2005.

36. Udesky L. The ethics of direct-to-consumer genetic testing. Lancet 2010;376(9750):1377-8. [published Online First: 2010/10/28]

37. Hogarth S, Javitt G, Melzer D. The current landscape for direct-to-consumer genetic testing: legal, ethical, and policy issues. Annu Rev Genomics Hum Genet 2008;9:161-82. doi: 10.1146/annurev.genom.9.081307.164319 [published Online First: 2008/09/05]

38. Gray SW, Gollust SE, Carere DA, et al. Personal Genomic Testing for Cancer Risk: Results From the Impact of Personal Genomics Study. J Clin Oncol 2017;35(6):636-44. doi: 10.1200/JC0.2016.67.1503 [published Online First: 2016/12/13]

39. Carere DA, VanderWeele T, Moreno TA, et al. The impact of direct-toconsumer personal genomic testing on perceived risk of breast, prostate, colorectal, and lung cancer: findings from the PGen study. BMC Med Genomics 2015;8:63. doi: 10.1186/s12920-015-0140-y [published Online First: 2015/10/16]

40. McGuire AL, Evans BJ, Caulfield T, et al. Science and regulation. Regulating direct-to-consumer personal genome testing. Science 2010;330(6001):181-2. doi: 10.1126/science.1194006 [published Online First: 2010/10/12] 
41. Ngeow J, Eng C. Precision medicine in heritable cancer: when somatic tumour testing and germline mutations meet. NPJ Genom Med 2016;1:15006. doi: 10.1038/npjgenmed.2015.6 [published Online First: 2016/01/13]

42. Levy DE, Garber JE, Shields AE. Guidelines for genetic risk assessment of hereditary breast and ovarian cancer: early disagreements and low utilization. J Gen Intern Med 2009;24(7):822-8. doi: 10.1007/s11606-0091009-6 [published Online First: 2009/05/21]

43. Ngeow J, Sesock K, Eng C. Breast cancer risk and clinical implications for germline PTEN mutation carriers. Breast Cancer Res Treat 2017;165(1):18. doi: 10.1007/s10549-015-3665-z [published Online First: 2015/12/25]

44. Stephens PJ, Tarpey PS, Davies H, et al. The landscape of cancer genes and mutational processes in breast cancer. Nature 2012;486(7403):400-4. doi: 10.1038/nature11017 [published Online First: 2012/06/23]

45. Chadwick RF, Levitt M, Shickle D. The right to know and the right not to know : genetic privacy and responsibility. 2nd edition. ed.

46. Garraway LA. Genomics-driven oncology: framework for an emerging paradigm. J Clin Oncol 2013;31(15):1806-14. doi: 10.1200/JC0.2012.46.8934 [published Online First: 2013/04/17]

47. Parker M. Ethical problems and genetics practice. New York: Cambridge University Press 2012. 